\title{
Irrigation and Deep Tillage Effects on Pesticide Use and Water Productivity of Dry Seeded Rice
}

\author{
Ritika Joshi* \\ Punjab Agricultural University \\ *Corresponding author
}

A B S T R A C T

\begin{tabular}{|l|}
\hline K e y w o r d s \\
$\begin{array}{l}\text { Dry-seeded rice, } \\
\text { Tillage regimes, } \\
\text { Irrigation regimes, } \\
\text { Water use efficiency. }\end{array}$ \\
\hline Article Info \\
\hline $\begin{array}{l}\text { Accepted: } \\
\text { 20 September } 2017 \\
\text { Available Online: } \\
\text { 10 November } 2017\end{array}$ \\
\hline
\end{tabular}

\section{Introduction}

Rice (Oryza sativa L.) is an important cereal food for more than half of the global population. About 55 per cent of the rice area is irrigated that accounts for 75 percent of the rice production in the world (Bouman, 2001). Rice is a major user of freshwater accounting for approximately 50 per cent of the total diverted fresh water in Asia. Irrigated lowland rice is the most important agricultural ecosystem in Asia, and the food security of most of its population depends on it.
The irrigated rice-wheat (RW) cropping system of north-west India is fundamental to India's food security (Timsina and Connor, 2001). Productivity and profitability of rice is high under alluvial irrigated tract of Punjab and groundwater is the primary source for irrigation. Flood-irrigated rice utilizes two or three times more water than other cereal crops such as maize and wheat. However, large amount of water input in rice culture has led to over-exploitation of groundwater as 
indicated by alarming fall in water table. Average fall in water table in central region of the state has been more than $0.75 \mathrm{~m}$ year-1 in the last decade (Minhas et al., 2010 and Humphreys et al., 2010) that threatens sustainability of rice production. This fall has resulted in increased energy requirement and cost of pumping groundwater, increased tube well installation cost and deteriorated the ground water quality (AICRP 2009, Kamra et al., 2002). Thus, there is a need to explore alternate techniques that can sustain rice production and are resource conservative.

On the face of global water scarcity and escalating labour rates, when the future of rice production is under threat, direct-seeded rice offers an attractive alternative (Farooq et al., 2011). Direct sowing of rice refers to the process of establishing a rice crop from seeds sown in the field rather than transplanting seedlings from the nursery. At present, 23 per cent of rice is direct-seeded globally (Rao et al., 2007). Direct-seeded rice is a resource conservation technology as it uses less water with high efficiency, incurs low labour expenses and is conducive to mechanization (Bhuiyan et al., 1995). Low wages and adequate water favors transplanting, whereas high wages and low water availability suit direct-seeded rice (Pandey and Velasco 2005). Direct-seeded rice can be categorized as (1) Wet, in which sprouted rice seeds are broadcast or sown in lines on puddled soil, and (2) Dry, in which dry rice seeds are broadcast on unpuddled soil. Dry seeding of rice with subsequent aerobic soil conditions avoids water application for puddling and maintenance of submerged soil conditions, and thus reduces the overall water demand (Bouman, 2001; Sharma et al., 2002). Dryseeded rice (DSR) provides an opportunity for earlier crop establishment to make better use of early season rainfall and to increase crop intensification in some rice based system (Tuong, 2000).
As soil water dynamics in dry-seeded rice is different from that of puddle transplanted rice, this is likely to affect water and nutrient uptake, and ensuing growth and crop yields. In semi-arid subtropical climatic conditions, dry-seeded rice is expected to respond (like maize) to changes in soil physical environment caused by deep tillage resulting in improved crop productivity. Deep tillage has emerged as a better option to improve deep root growth (advantageous for water extraction during drought in upland rice) of rice cultivars. Tillage under intensive cropping system has the additional challenges of ensuring high water use, nutrient use and energy use efficiencies through deeper and denser crop rooting (Gajri et al., 2002).

\section{Materials and Methods}

A field experiment was conducted for cropping seasons 2012 at Punjab Agricultural University Research Farm, Ludhiana, India (30054' N, 75048'70 E, 247 m above mean sea level). The experimental soil was a sandy loam having $75 \%$ sand, $10 \%$ clay and $0.41 \%$ organic carbon in the top $0.30 \mathrm{~m}$ layer. The soil is slightly alkaline $(\mathrm{pH} 8.0)$ and nonsaline. The groundwater was more than $15 \mathrm{~m}$ deep. Weather parameters in respect of monthly mean maximum and minimum temperature, sunshine hours, cumulative rainfall and pan-evaporation (US weather Bureau Class A pan) for cropping seasons are given in Table 1. Combinations of two tillage treatment and two irrigation regimes (Irrigation based on IW/CPE ratio of $2.4\left(\mathrm{I}_{2.4}\right)$ and $1.2\left(\mathrm{I}_{1.2}\right)$ can be evaluated in a split-plot design with three replications. The tillage regimes included conventional tillage (CT)soil manipulation to $0.10 \mathrm{~m}$ depth by two runs of a disc harrow, two runs of a tine cultivator followed by planking; and deep tillage (DT) sub-soiling with a chisel $0.35 \mathrm{~m}$ deep and $0.40 \mathrm{~m}$ apart followed by CT. After harvest of preceding wheat, the fields were irrigated in 
the last week of April. In order to impose DT treatment, the plots were sub-soiled in the last week of May by which time the sub-soil had dried enough to permit maximum shattering. The plots were irrigated again before seedbed preparation by $\mathrm{CT}$ as described. Cultivar was seeded@30 kg ha ${ }^{-1}$ in rows $0.20 \mathrm{~m}$ apart at soil depth of $0.02-0.03 \mathrm{~m}$ with a seed-drill on June 7. The crop was fertilized with $150 \mathrm{~kg} \mathrm{~N}$ (urea), $30 \mathrm{~kg} \mathrm{P}_{2} \mathrm{O}_{5}$ (single super phosphate), $30 \mathrm{~kg} \mathrm{~K}_{2} \mathrm{O}$ (murate of potash) and $25 \mathrm{~kg}$ $\mathrm{ZnSO} 4$ per $\mathrm{ha}^{-1}$. The crop was protected against weed, disease and insect incidents by following local recommendations. Weeds were controlled by applying Pendimethalin @ $2.51 \mathrm{ha}^{-1}$ within two days of sowing followed by Bispyribac@ $250 \mathrm{ml} \mathrm{ha}^{-1} 30$ days after sowing and one manual hoeing 40-45 days after sowing. The crop was harvested in the first fortnight of October. Soil water was monitored by gravimetric method at $0.30 \mathrm{~m}$ depth increments in the top $0.90 \mathrm{~m}$ profile at sowing and at harvest. Soil cores for determining root growth (depth and density of rooting) were sampled 80 days after sowing (panicle emergence stage) during cropping season at $0.10 \mathrm{~m}$ depth increments to the depth until which roots were encountered with a $0.05 \mathrm{~m}$ diameter auger centered 0.025 $\mathrm{m}$ away from the plant base. Roots from each sample were washed with a gentle flush of water in a 1-mm sieve, cleaned, dried, weighed and expressed as root mass density $\left(\mathrm{ug} \mathrm{cm} \mathrm{cm}^{-3}\right.$ ). Treatment effects on crop yield and yield attributes were tested for statistical significance using analysis of variance (ANOVA). Irrigation-based water productivity (WPI) was computed as the ratio of grain yield to seasonal irrigation amount.

\section{Results and Discussion}

\section{Root growth}

Rooting profiles of DSR at 80 days after sowing (panicle emergence stage) in relation to tillage and irrigation regimes is given in
Figure 1. It is shown that although depth of rooting $(0.30 \mathrm{~m})$ was not affected by the treatments, but root proliferation in terms of root mass density (RMD) was significantly influenced. Tillage and irrigation had significant effects on RMD. Among tillage and irrigation regimes, root mass density was highest in CT $\mathrm{I}_{2.4}$ followed by DT $\mathrm{I}_{2.4}, \mathrm{CT} \mathrm{I}_{1.2}$ and DT $\mathrm{I}_{1.2}$. It varied from 838, 837, 734 and $724 \mu \mathrm{g} \mathrm{cm}^{-3}$, respectively. Total root mass in $\mathrm{CTI}_{1.2}, \mathrm{CTI}_{2.4}, \mathrm{DTI}_{1.2}$ and $\mathrm{DTI}_{2.4}$ regimes was $78,93,82,93$ and $15093 \mathrm{~g} \mathrm{~m}^{-2}$; while root mass below $0.10 \mathrm{~m}$ soil depth was $4.2,8.8$, 9.7 and $9.4 \mathrm{~g} \mathrm{~m}^{-2}$ for the four treatments. It implies that effects of irrigation and deep tillage on root mass density were greater below $0.10 \mathrm{~m}$ soil depth.

\section{Moisture dynamics}

Figures 2 shows the effect of irrigation and tillage regimes on depth distribution of soil water at 35, 70 DAS and at harvest. Differential irrigation was imposed as per the treatment at 57 DAS. Depth- wise soil water content changes under different tillage regimes at 35 DAS. However, there was no consistent effect of tillage on moisture content in top $60 \mathrm{~cm}$. Soil water profiles at 70 DAS indicate irrigation or tillage effects. Soil water content in different layers was generally higher in $\mathrm{I}_{2.4}$ than $\mathrm{I}_{1.2}$ regimes. Among tillage and irrigation regimes, profile moisture content ranged from 15.6-15.5, 14.9-16.6, 14.8-15.6 and 14.2-15.9 \% in CT $\mathrm{I}_{2.4}, \mathrm{DT} \mathrm{I}_{2.4}$, CT $\mathrm{I}_{1.2}$ and DT $\mathrm{I}_{1.2}$ treatments. At 70 DAS water was also extracted from $30-60 \mathrm{~cm}$ depths in all the treatments.

Harvest time moisture profiles shows that soil water content in $0-60 \mathrm{~cm}$ soil layers was consistently higher in $\mathrm{CT} \mathrm{I}_{2.4}$ regimes, compared to the tillage and irrigation regimes. Among tillage and irrigation regimes, profile moisture content ranged from 11.2-15.6, 13.2$16.1,9.9-14.4$ and $10.2-15.6 \%$ at $\mathrm{CT}_{2.4}$, DT $\mathrm{I}_{2.4}, \mathrm{CT} \mathrm{I}_{1.2}$ and DT $\mathrm{I}_{1.2}$. Profile moisture 
content increases with increased in depths at harvest in all the treatments. The total amount of water extraction from the whole profile $(0$ $90 \mathrm{~cm}$ ) at harvest differed little among the treatments.

\section{Water use efficiency}

Effect of irrigation and tillage regimes on water use efficiency is presented in Table 2.
Among tillage and irrigation regimes, highest irrigation and total water use efficiency was observed in DT $\mathrm{I}_{1.2}$ followed by DT $\mathrm{I}_{2.4}$, CT $\mathrm{I}_{2.4}$ and lowest in $\mathrm{CT} \mathrm{I}_{1.2}$ and irrigation water use efficiency varied from 4.00, 3.53, 2.69 and $2.58 \mathrm{~kg} \mathrm{ha}^{-1} \mathrm{~mm}^{-1}$. Higher water use efficiency in DT was probably due to increased grain yield through enhancing water and nutrient uptake from deeper layers under water deficit conditions.

Fig.1 Effect of irrigation and tillage regimes on root mass density profiles of dry-seeded rice at $80 \mathrm{DAS}$
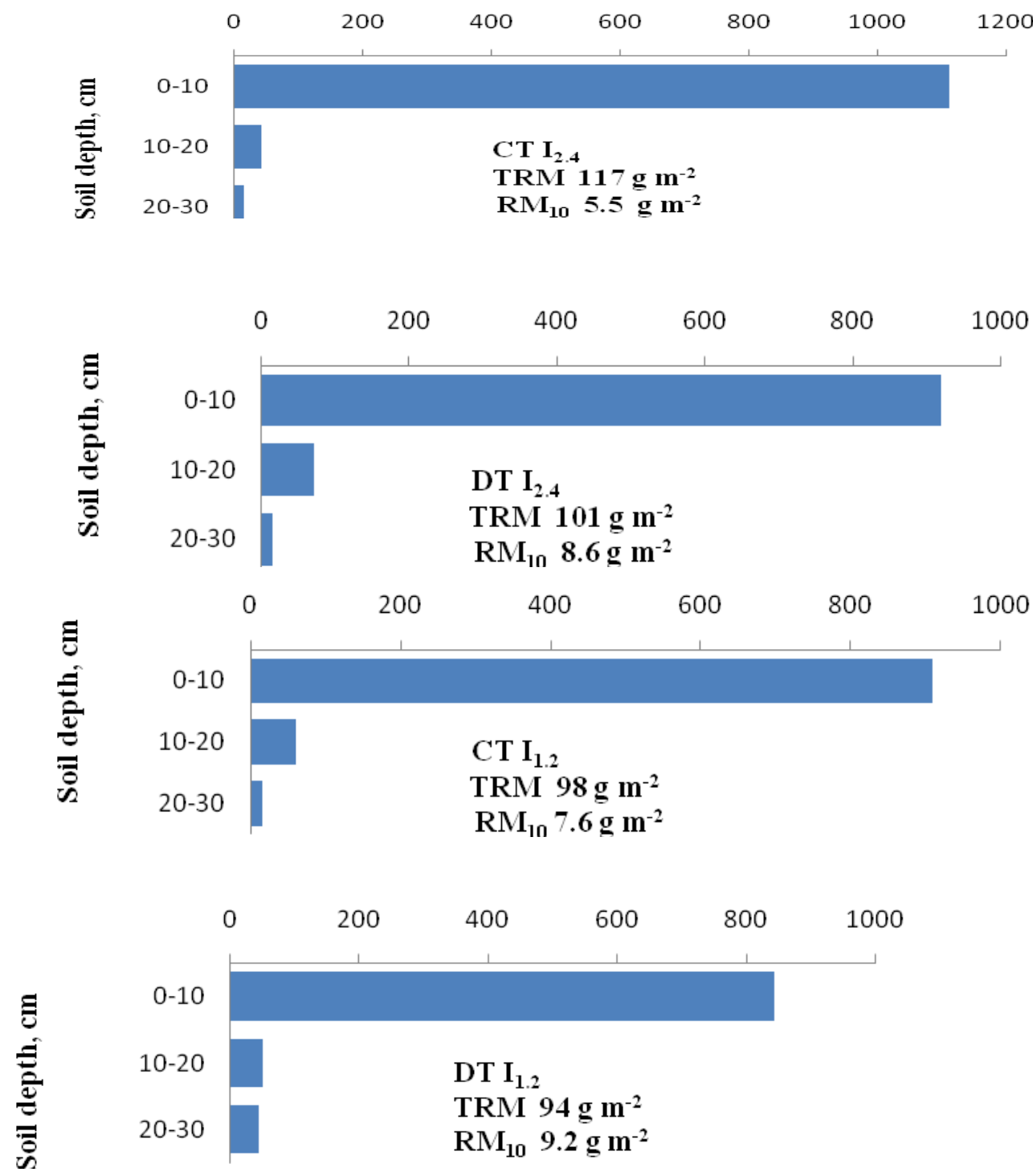

Root mass density $\left(\mu \mathrm{g} \mathrm{cm}^{-3}\right)$ 
Fig.2 Effect of irrigation and tillage regimes on soil moisture profiles of dry-seeded rice at 35, 70 DAS and at harvest
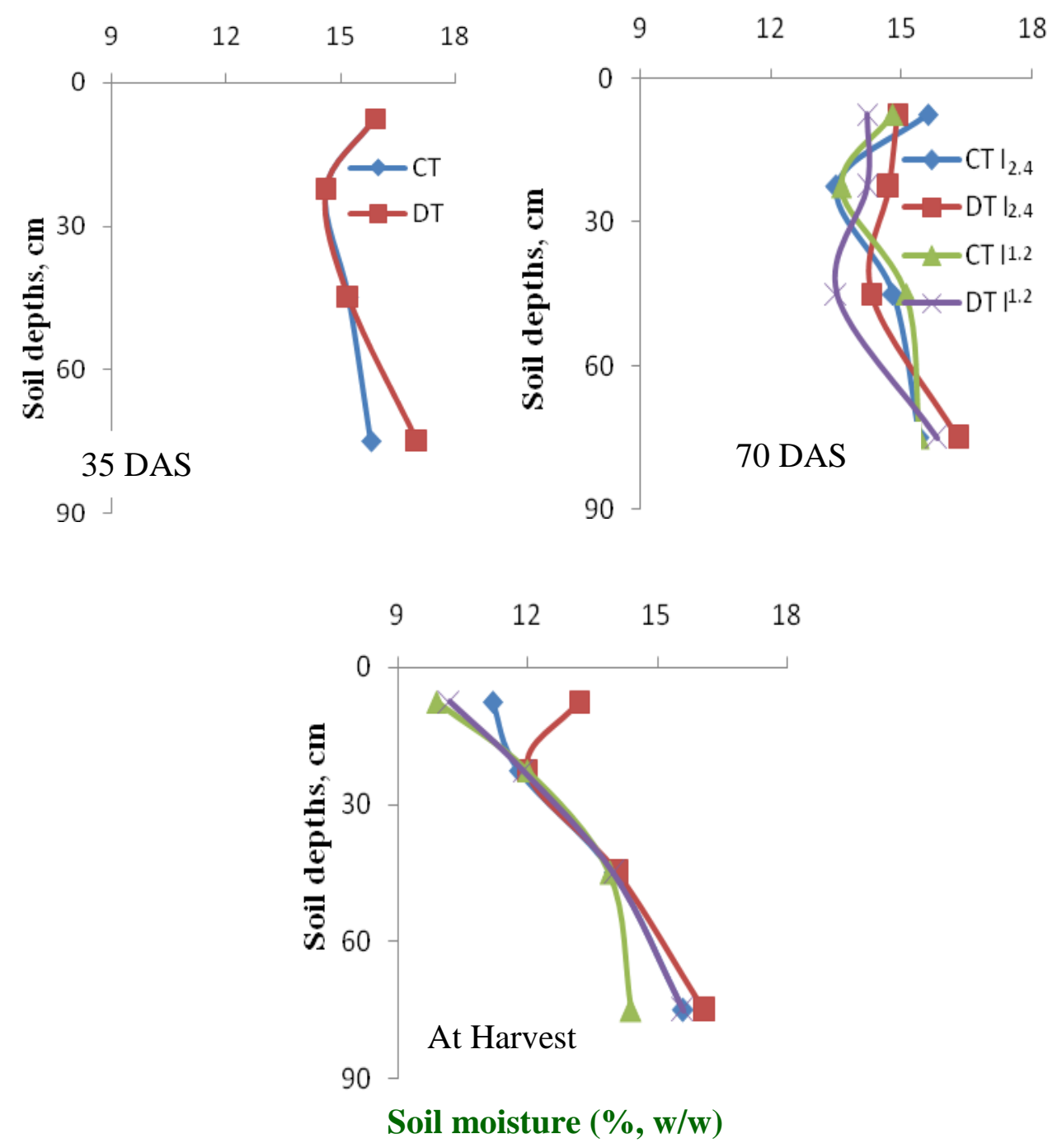

Table.1 Mean monthly meteorological parameters during kharif 2012

\begin{tabular}{|r|c|c|l|l|l|c|}
\hline \multirow{2}{*}{ Month } & \multicolumn{2}{|l|}{ Air temp. $\left({ }^{\circ} \mathbf{C}\right)$} & $\begin{array}{l}\text { Rainfall } \\
(\mathbf{m m})\end{array}$ & $\begin{array}{l}\text { Evaporation } \\
(\mathbf{m m})\end{array}$ & $\begin{array}{l}\text { Sunshine } \\
(\mathbf{h r s})\end{array}$ \\
\cline { 2 - 7 } & Max. & Min. & Mean & 3.5 & 315 & 8.9 \\
\hline June & 40.6 & 27.2 & 33.9 & 3.5 & 6.6 \\
\hline July & 35.7 & 27.9 & 31.8 & 76.9 & 212.1 & 4.5 \\
\hline Aug & 33.2 & 26.6 & 29.9 & 160.4 & 120.2 & 7.81 \\
\hline Sept & 32.8 & 23.9 & 28.4 & 141.7 & 109.0 & 8.7 \\
\hline Oct & 31.6 & 16.2 & 23.9 & 0.0 & 107.0 & \\
\hline
\end{tabular}


Table.2 Effect of irrigation and tillage regimes on water use efficiency of dry-seeded rice in relation to cultivars

\begin{tabular}{|c|c|c|}
\hline \multicolumn{2}{|c|}{ Irrigation water use efficiency } & \multirow[t]{2}{*}{ Total water input use efficiency } \\
\hline$\left(\mathrm{kg} \mathrm{ha}^{-1} \mathrm{~mm}^{-1}\right)$ & $\left(\mathrm{kg} \mathrm{ha}^{-1} \mathrm{~mm}^{-1}\right)$ & \\
\hline Irrigation and tillage regimes & PR114 & PR114 \\
\hline CT I I $_{2.4}$ & 2.69 & 2.16 \\
\hline DT $\mathbf{I}_{2.4}$ & 3.53 & 2.84 \\
\hline CT $\mathrm{I}_{1.2}$ & 2.58 & 1.96 \\
\hline DT $\mathbf{I}_{1.2}$ & 4.00 & 3.04 \\
\hline
\end{tabular}

\section{Root growth}

Among tillage and irrigation regimes, root mass density was highest in CT $\mathrm{I}_{2.4}$ followed by DT $\mathrm{I}_{2.4}, \mathrm{CT} \mathrm{I}_{1.2}$ and DT $\mathrm{I}_{1.2}$. It varied from $838,837,734$ and $724 \mu \mathrm{g} \mathrm{cm}^{-3}$, respectively. Total root mass in $\mathrm{CTI}_{1.2}, \mathrm{CTI}_{2.4}, \mathrm{DTI}_{1.2}$ and $\mathrm{DTI}_{2.4}$ regimes was 78, 93, 82, 93 and 15093 $\mathrm{g} \mathrm{m}^{-2}$; while root mass below $0.10 \mathrm{~m}$ soil depth was 4.2, 8.8, 9.7 and $9.4 \mathrm{~g} \mathrm{~m}^{-2}$ for the four treatments. It implies that effects of irrigation and deep tillage on root mass density were greater below $0.10 \mathrm{~m}$ soil depth.

Deep tillage effects on root mass density were more than that of irrigation, and this effect being greater in $\mathrm{I}_{1.2}$ than in $\mathrm{I}_{2.4}$ regime. Kato et al., (2007) reported that deep tillage caused greater root mass below $0.30 \mathrm{~m}$ soil depth compared to conventional tillage in rain-fed upland in a temperate climate in Japan.

\section{Moisture dynamics}

Within a given irrigation regimes, DT had low moisture than CT. At 70 DAS, profile soil moisture storage was lowest $(19.6 \mathrm{~cm})$ in DT $\mathrm{I}_{1.2}$ treatment followed by CT $\mathrm{I}_{1.2}, \mathrm{CT} \mathrm{I}_{2.4}$ and highest in DT $\mathrm{I}_{2.4}(20.5 \mathrm{~cm})$ in both the cultivars. This reduction in profile soil moisture storage was probably due to more uptake of water from deeper layers with DT under water deficit conditions.

\section{Water use efficiency}

Among tillage and irrigation regimes, highest irrigation and total water use efficiency was observed in DT $\mathrm{I}_{1.2}$ followed by DT $\mathrm{I}_{2.4}, \mathrm{CT}$ $\mathrm{I}_{2.4}$ and lowest in $\mathrm{CT} \mathrm{I}_{1.2}$ and irrigation water use efficiency varied from 4.00, 3.53, 2.69 and $2.58 \mathrm{~kg} \mathrm{ha}^{-1} \mathrm{~mm}^{-1}$. Higher water use efficiency in DT was probably due to increased grain yield through enhancing water and nutrient uptake from deeper layers under water deficit conditions. Shekara et al., (2010) also reported that lesser irrigation water to cumulative pan evaporation ratio leads to higher water use efficiency and found that irrigation scheduled at $\mathrm{I}_{1.0}$ showed higher water use efficiency $\left(5.21 \mathrm{~kg} \mathrm{ha}^{-1} \mathrm{~mm}^{-1}\right)$. Ramamoorthy et al., (1996) also reported that the water use efficiency was highest under medium moisture range.

\section{Acknowledgement}

I am very thankful to my advisor, advisory committee, soil science department and farm during my research.

\section{References}

AICRP. 2009 All India Coordinated Project on Management of salt Affected Soils and Use of Saline Water in Agriculture Biennial Report (2006-08). Central Soil Salinity 
Research Institute, Karnal, Haryana, India, $212 \mathrm{pp}$.

Bhuiyan, S. I., M. A., Sattar, and Khan, M. A. K. 1995 Improving water use efficiency in rice irrigation through wet seeding. Irrigation Science 16: 1-8.

Bouman, B. A. M., and Tuong, T. P. 2001 Field water management to save water and increase its productivity in irrigated rice. Agricultural Water Management 49: 11-30.

Farooq, M, H. M., Kadambot, H. Rehman, T. Aziz, Dong-jin Lee, and Wahid. A. 2011 Rice direct seeding: Experience challenges and opportunities. Soil Tillage Research 111: 87-98.

Gajri, P. R., V. K. Arora, a nd Parihar, S. S. 2002 Tillage for sustainable cropping. New York, Food Products Press.

Humphreys, E., S. S. Kukal, E. W.Christen, Balwinder-Singh, Sudhir-Yadav, and Sharma, R. K. 2010 Halting the ground water decline in north west India- which crop technologies will be winners? Advances Agronomy 109: 155-217.

Kamra, S. K., Khajanchi Lal, and Boonstra, J. 2002 Effects of pumping on temporal changes in groundwater quality. Agricultural Water Management 56: 169-178.

Kato, Y., A. Kamoshita, Abe jun, and Yamagishi, J. 2007 Improvement of rice growth in upland conditions with deep tillage and mulch. Soil Tillage Research 92: 30-44.

Minhas, P. S.,S. K. Jalota, V. K. Arora, A. K. Jain, K. K. Vashist, O. P. Choudhary, S. S. Kukal, and Vashisht, B. B. 2010 Managing water resources for ensuring sustainable agriculture: situational analysis and options for Punjab. Research Bulletin 2/2010, Directorate of Research, Punjab Agricultural University, Ludhiana-141004 (India) p. 40.

Pandey, S. and Velasco, L. E. 2005 Trends in crop establishment methods in Asia and research issues. In: Rice is Life: Scientific Perspectives for the $21^{\text {st }}$ Century, Proceedings of the World Rice Research Conference, 4-7 November 2004, Tsukuba, Japan, pp: 178-81.

Ramamoorthy, K., A. Arokiaraj, and Balasubramanian, A. 1996 Response of upland direct- seeded rice to soil-moisture regime and weed control. Indian Journal Agronomy 43: 82-86.

Rao, A. N., D. E. Johnson, B. Sivaprasad, J. K. Ladha, and Mortimer, A. M. 2007 Weed management in direct seeded rice. Advances Agronomy 93: 153-255.

Sharma, P. K., L. Bhushan, J. K. Ladha, R. K. Naresh, R. K. Gupta, B. Balasubramanian, and Bouman, B. A. M. 2002 Crop-water relations in rice-heat cropping under different tillage systems and water management practices in a marginally sodic medium textured soil. In: Bouman B A M, Hengsijk H, Hardy B, Bihdraban B, Tuong $\mathrm{T} \mathrm{P}$ and Ladha $\mathrm{J} \mathrm{K}$ (eds) Proceedings of the International Workshop on Water-wise Rice Production. International Rice Research Institute, Los Banos, Philippines, pp: 223-235.

Shekara, B. G., Sharnappa, and Krishnamurthy, N. 2010 Effect of irrigation schedules on growth and yield of aerobic rice under varied levels of farmyard manure in Cauvery command area. Indian Journal Agronomy 55: 35-39.

Timsia, J. and Connor, D. J. 2001 Productivity and management of rice-wheat cropping systems: Issues and challenges. Field Crops Research 69: 93-132.

Tuong, T. P., A. K. Singh, J. Siopongco, and Wade, L. J. 2000 Constraints to high yield of dry seeded rice in the rainy season in a humid tropic environment. Plant Production Science 3: 164-172.

\section{How to cite this article:}

Ritika Joshi. 2017. Irrigation and Deep Tillage Effects on Pesticide Use and Water Productivity of Dry Seeded Rice. Int.J.Curr.Microbiol.App.Sci. 6(11): 2773-2779.

doi: https://doi.org/10.20546/ijcmas.2017.611.328 